\title{
Prevalens av hjemmerespiratorbehandling i Norge
}

\begin{abstract}
Sammendrag
Bakgrunn. Bruken av hjemmerespirator er økende i Norge. Det skjer uten at det foreligger klare internasjonale eller nasjonale retningslinjer for oppstart eller gjennomføring av slik behandling. Nasjonalt register for hjemmerespiratorbehandling ble startet i 2002. I denne artikkelen beskrives omfang av og regionale variasjoner i hjemmerespiratorbehandling.
\end{abstract}

Materiale og metode. Studien er basert på data registrert i Nasjonalt register for hjemmerespiratorbehandling i perioden 1.1. 2002-31.12. 2007.

Resultater. I tidsrommet 2002-07 registrerte 31 sykehus 1282 hjemmerespiratorpasienter - 133 barn $161,7 \%$ gutter) og 1149 voksne (54,3\% menn). Aldersspredningen var 5 md. - 93 år. $19 \%$ av barna og $7 \%$ av de voksne var trakeostomert. Prevalensen av hjemmerespiratorbehandling per 31.12. 2007 var 19,9/100 000 innbyggere. Prevalensen varierte hos barn fra 1,8/ 100000 (Helse Sør-Øst) til 5/100 000 (Helse Nord), hos voksne fra 13/100 000 (Helse Midt-Norge) til 31/100 000 (Helse Nord). Det var store variasjoner mellom de enkelte helseregioner når det gjaldt forekomst av hjemmerespiratorbehandling i ulike sykdomsgrupper.

Fortolkning. Studien viste store regionale variasjoner i hjemmerespiratorbehandling til barn og voksne. Ulik bruk av slik behandling gir et uforutsigbart og geografisk varierende tilbud til pasientene.

\section{Elin Tollefsen}

elin.tollefsen@ntnu.no

Nasjonalt register for

hjemmerespiratorbehandling

Lungeavdelingen

Haukeland universitetssykehus

5021 Bergen

Lungeavdelingen

St. Olavs hospital

\section{Amund Gulsvik}

Per Bakke

Lungeavdelingen

\section{Ove Fondenes}

Nasjonalt kompetansesenter

for hjemmerespiratorbehandling Lungeavdelingen

Haukeland universitetssykehus

Hjemmerespiratorbehandling kan være et godt alternativ for pasienter med kronisk respirasjonssvikt på bakgrunn av hypoventilasjon. Utredning og iverksettelse av behandlingen gjøres av barneleger, lungeleger og anestesileger. Nevrologer er viktige samarbeidspartnere ved nevrologisk grunnlidelse. Utgiftene på helseforetaksnivå skriver seg fra sykehusopphold, utstyr og forbruksmateriell.

Omfanget av hjemmerespiratorbehandling i Norge og i de fleste andre land har vært lite kjent. I to studier har man forsøkt å kartlegge prevalensen av slik behandling $\mathrm{i}$ en rekke europeiske land $(1,2)$. Konklusjonen i begge var mangelfull oversikt og at estimerte prevalenstall trolig var for lave i de fleste land.

Prevalensen av hjemmerespiratorbehandling i 2001-02 varierte fra 3,4/100 000 (Irland) til 17/100 000 (Frankrike) (2). I Sverige (prevalens 10/100 000) har man hatt et nasjonalt register for hjemmerespiratorbehandling siden 1996 (3), i Norge siden 2002.

Pasientgruppen er heterogen når det gjelder diagnoser, alderssammensetning og prognose. Forbedret livskvalitet og livsforlengelse, eller livsopprettholdelse, er målsettingene for behandlingen.

De medisinske kriteriene for oppstart er ikke veldefinerte (3), og ikke i noe europeisk land er det klare retningslinjer og behandlingsstrategier for hjemmerespiratorbehandling $(1,2)$. Hensikten med denne studien var å kartlegge omfang av og regionale variasjoner i hjemmerespiratortilbudet for barn og voksne i Norge.

\section{Materiale og metode}

Nasjonalt register for hjemmerespiratorbehandling ble opprettet og satt i funksjon 1.1. 2002 av Nasjonalt kompetansesenter for hjemmerespiratorbehandling (NKH). Registeret eies av Lungeavdelingen ved Haukeland universitetssykehus og finansieres av Helse Vest RH. Det er godkjent av Datatilsynet og av regional komité for medisinsk forskningsetikk (REK), som også har godkjent denne studien.

Registeret inkluderer pasienter som er varig avhengig av ventilasjonsstøtte hele eller deler av døgnet. Behandlingsmetoden er positivt luftveistrykk med to ulike nivåer (bilevel positive airway pressure ventilation, BiPAP) med innstilt respirasjonsfrekvens (spontaneous-timed modus) eller trykk- og/ eller volumkontrollert respirator. Respiratortilslutningen kan skje via maske/munnstykke eller via trakeostomi (2-4). Inklusjonskriteriet for barn under 18 år omfatter også dem som bruker kontinuerlig luftveisovertrykk (continuous positive airway pressure ventilation, CPAP). Voksne brukere av CPAP-ventilasjon og pasienter med BiPAPventilasjon på grunn av obstruktiv søvnapné er ikke inkludert i registeret.

Innsamlede data fra sykehus i Norge er basis for registeret. Et standardisert spørreskjema (5) fylles ut av behandlende lege eller delegert sykepleier. Pasienter som startet behandlingen før opprettelsen av registeret kan bli etterregistrert på et forenklet skjema. Studien omfatter opplysninger om kjønn, alder, hoveddiagnose, behandlingsmetode, ventilatortilslutning og helseregion innrapportert i perioden 1.1. 2002-31.12. 2007. Sammen med rapport om status for virksomheten ved det enkelte sykehus sender registeret årlig ut (fra 2006) et standardisert oppfølgingsskjema som skal utfylles av

\section{Hovedbudskap}

- Prevalensen av hjemmerespiratorbehandling i Norge per 31.12. 2007 var 19,9/100 000

- Det forelå et stort antall grunnlidelser hos både barn og voksne

- De fleste pasientene (92\%) hadde maske som ventilatortilslutning

- Det var store regionale variasjoner i indikasjonsstilling og i bruk av hjemmerespiratortilbudet 
pasientansvarlige leger. Skjemaet har en post for avsluttet behandling/dato for død. Registreringen er frivillig for den enkelte pasient, og det er krav om skriftlig informert samtykke. Pasientinformasjonsskriv og samtykkeerklæring er elektronisk tilgjengelig (5). Registerdata t.o.m. 31.12. 2007 ble kvalitetssikret ved at leger ved alle sykehus, også sykehus som ikke hadde rapportert pasienter, ble kontaktet (telefonisk eller via elektronisk post). Dette for å sikre komplett rapportering, supplere mangelfullt utfylte skjemaer og innhente oppfølgingsskjemaer.

I undersøkelsen har vi gjort deskriptiv statistikk ved hjelp av frekvenstabeller. Prevalens av hjemmerespiratorbehandling per 31.12. 2007 angis som antall pasienter med pågående behandling/100 000 innbyggere. «Barn» ble definert som dem som var $<18$ år ved behandlingsstart, «voksne» dem som var $\geq 18$ år

\section{Resultater}

31.12. 2007 hadde 31 sykehus meldt hjemmerespiratorpasienter til registeret. De 12 største sykehusene i landet hadde rapportert $90 \%$ av pasientene, 11 sykehus hadde rapportert under fem pasienter hver. Totalt 1282 pasienter $(55,1 \%$ av hannkjønn $)$ var innmeldt, derav 133 barn (61,7\% gutter). Hos barn var aldersspredningen 5 md. -17 år (gjennomsnitt åtte år), hos voksne 18-93 år (gjennomsnitt 58 år). Av totalpopulasjonen var 301 pasienter $(56,5 \%$ av hannkjønn) med behandlingsstart 1961-2001 etterregistrert på forenklet skjema, derav 49 barn $(59,2 \%$ gutter $)$ og 252 voksne $(56,0 \%$ menn).

Innen utgangen av 2007 var ti av barna døde $(7,5 \%)$, fem $(3,8 \%)$ hadde avsluttet behandlingen og $118(88,7 \%)$ var fortsatt under behandling, av de voksne var det 252 døde $(21,9 \%), 72(6,3 \%)$ hadde avsluttet behandlingen og $825(71,8 \%)$ var fortsatt under behandling (fig 1). Prevalensen av hjemmerespiratorbehandling per 31.12. 2007 var $19,9 / 100000$, for barn var den 2,4/100 000 .

I barnegruppen ble 40 diagnoser registrert, derav 29 diagnoser hos kun ett barn (tab 1). Hos voksne ble det innmeldt 30 forskjellige diagnoser (tab 2).

I totalpopulasjonen hadde $7,8 \%$ ventilatortilslutning via trakeostomi, de resterende $92,2 \%$ ble ventilert via maske. Av barna ble $18,8 \%$ ventilert via trakeostomi, av voksne 6,5\%. Amyotrofisk lateral sklerose (ALS) $(\mathrm{n}=22)$, Duchennes/Beckers muskeldystrofi $(n=13)$ og høy ryggmargsskade/tverrsnittslesjon $(\mathrm{n}=12)$ var de vanligste diagnosene i trakeostomigruppen. Alle pasienter med stabil kronisk obstruktiv lungesykdom (kols) og adipositashypoventilasjonssyndrom ble ventilert via maske. Av barna var det hos $69,9 \%$ BiPAP-ventilasjon, hos 3,8 \% CPAP-ventilasjon og hos $26,3 \%$ trykk- og/ eller volumkontrollert respirator, av de voksne benyttet $88,3 \%$ BiPAP-ventilasjon

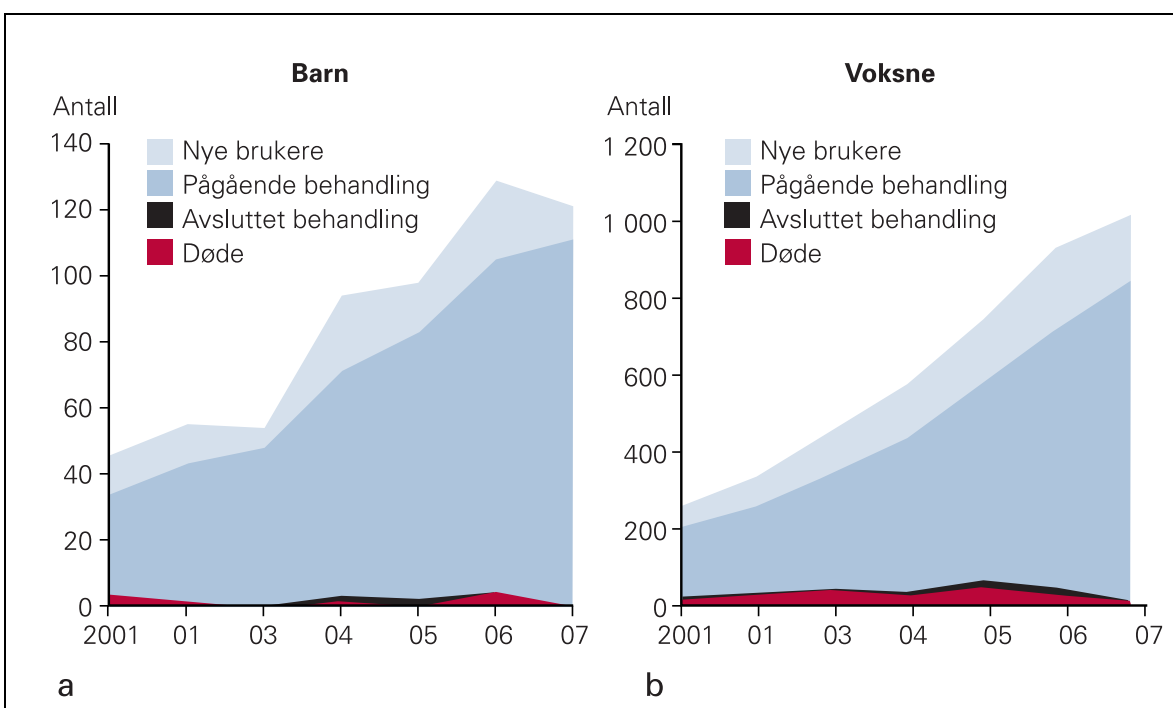

Figur 1 Hjemmerespiratorbehandling for al barn og bl voksne i perioden 2001-07 i Norge. Voksne er definert som dem $\geq 18$ år

og $11,7 \%$ trykk- og/eller volumkontrollert respirator.

Hos barn varierte prevalensen av hjemmerespiratorbehandling fra $1,8 / 100000 \mathrm{i}$ Helse Sør-Øst til 5/100 000 i Helse Nord, hos voksne fra 13/100 000 i Helse MidtNorge til 31/100 000 i Helse Nord (fig 2). Ved nevromuskulære sykdommer varierte hjemmerespiratorbruken fra 8,1/100 $000 \mathrm{i}$ Helse Midt-Norge til 14,5/100 000 i Helse Nord, forekomsten ved adipositashypoventilasjonssyndrom varierte fra 3,1/100 $000 \mathrm{i}$ Helse Midt-Norge til 8,8/100 000 i Helse Nord. Prevalensen av hjemmerespiratorbehandling ved stabil kols var høyest i Helse Nord (4,4/100 000) og i Helse Sør-Øst (4,2/

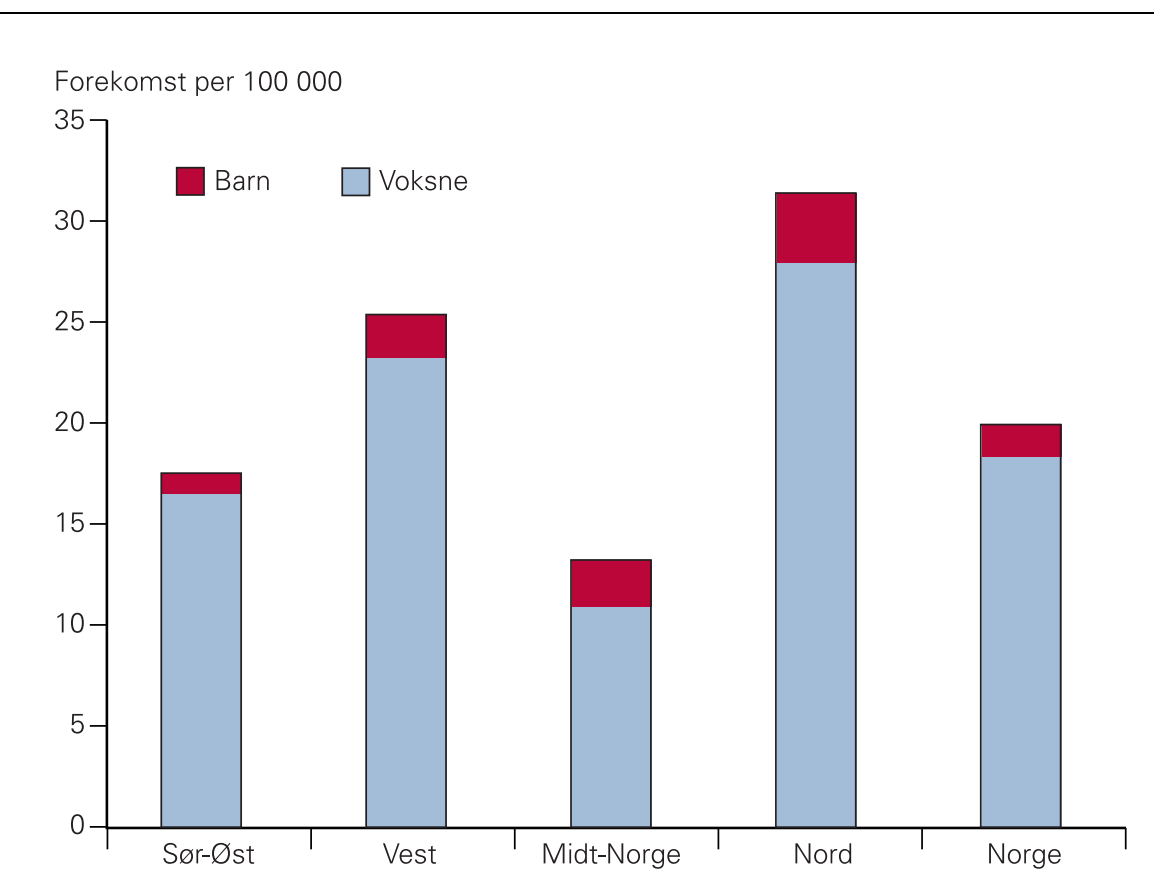

Figur 2 Hjemmerespiratorpasienter fordelt på de ulike helseregioner
100 000). Helse Midt-Norge hadde, uavhengig av diagnose, lavest prevalens av hjemmerespiratorbehandling (fig 3). Etter sammenslåing av tidligere Helseregion Sør og Helseregion Øst kamufleres geografiske variasjoner $\mathrm{i}$ hjemmerespiratortilbudet innad $\mathrm{i}$ Helse Sør-Øst, spesielt i forhold til enkeltdiagnoser som stabil kols (i Øst prevalens 2,3/100 000 og i Sør prevalens 7,5/100 000) og adipositashypoventilasjonssyndrom (i Øst prevalens 2,3/100 000 og i Sør prevalens $8,8 / 100000)$.

\section{Diskusjon}

Vår studie har vist at pasientgruppen som får hjemmerespiratorbehandling er mangeartet 
Tabell 1 Årsak til oppstart av hjemmerespiratorbehandling hos barn (133 barn totalt)

\begin{tabular}{lcr}
\hline Diagnoser & Antall & \multicolumn{1}{c}{$(\%)$} \\
\hline Spinal muskelatrofi (SMA) & 27 & $(20,3)$ \\
\hline $\begin{array}{l}\text { Duchennes muskeldystrofi } \\
\text { Annen muskeldystrofi }\end{array}$ & 20 & $(15,0)$ \\
\hline $\begin{array}{l}\text { Idiopatisk skoliose/skjelett- } \\
\text { dysplasi }\end{array}$ & 7 & $(5,8)$ \\
\hline $\begin{array}{l}\text { Sentralt hypoventilasjons- } \\
\text { syndrom }\end{array}$ & 7 & $(5,3)$ \\
\hline $\begin{array}{l}\text { Lungeparenkymsykdom } \\
\text { Cerebrale misdannelser }\end{array}$ & 6 & $(4,5)$ \\
\hline $\begin{array}{l}\text { Hjerneskade } \\
\text { Degenerativ hjernesykdom }\end{array}$ & 5 & $(3,8)$ \\
\hline $\begin{array}{l}\text { Høy ryggmargsskade/ } \\
\text { tverrsnittslesjon }\end{array}$ & 5 & $(3,8)$ \\
\hline $\begin{array}{l}\text { Mitokondriell sykdom } \\
\text { Polynevropati }\end{array}$ & 3 & $(3,8)$ \\
\hline Andre indikasjoner ${ }^{2}$ & 29 & $(21,3)$ \\
\hline $\begin{array}{l}\text { 1Symptomdebut etter første levemåned } \\
\text { 2For 29 diagnoser var kun ett barn registrert }\end{array}$ \\
\hline
\end{tabular}

når det gjelder diagnoser og alderssammensetning. De fleste brukere hadde maske, ikke trakeostomi, som ventilatortilslutning. Flere barn enn voksne var trakeostomerte. Studien viste at det var store geografiske variasjoner både hos barn og hos voksne og i omfang og diagnoser. Behandlingsindikasjonene var mange, men heller ikke når det gjaldt de vanligste diagnosene var det samsvar mellom bruken av hjemmerespirator i de ulike helseregionene.

I tidligere studier har man påpekt betydningen av nasjonale registre for å få holdbare prevalenstall over hjemmerespiratorbehandling (1, 2). I Eurovent-studien var prevalensen av slik behandling i Norge 7,8/ 100000 (2). Oppdaterte prevalenstall fra andre europeiske land er ikke publisert, men vi vil anta at det har vært vekst også $i$ andre land siden 2001-02 (2). Data fra det svenske registeret viste økning i prevalens av hjemmerespiratorbehandling fra 6,2 til 10,5 fra 1996 til 2002 (3), og i dag er prevalensen 18/100 000 (personlig meddelelse Bengt Midgren, Andningssviktregistret Swedevox). Behandlingstilbudet kan være kostbart, noe som kan bidra til et varierende tilbud i ulike land avhengig av hvordan helseforsikringen er ordnet.

Også i andre land har det vært påvist store regionale forskjeller. En seks års longitudinell prospektiv studie fra det svenske registeret for perioden 1996-2001 viste en økning i prevalens av hjemmerespiratorbehandling fra 14/100 000 til 22/100000 i ett fylke, mens den i et annet fylke økte fra 1/100 000 til 4/100 000 (3). I Norge er det ikke geografiske variasjoner i sykdomspanorama, men andre forhold kan påvirke forekomst og ulikheter i bruk av behandlingstilbudet. Grunnsykdommen er vesent- lig, men også hvordan respirasjonssvikten blir identifisert og fulgt opp. Pasientseleksjon og indikasjon for hjemmerespiratorbehandling kan variere ut fra den enkelte leges kunnskap om, erfaring med og holdning til behandlingen. Ved mange sykehus behandler man svært få eller ingen pasienter - det kan være uttrykk for at behandlingstilbudet ikke gis selv om medisinskfaglig indikasjon skulle være til stede.

Tradisjonelt har voksne hjemmerespiratorpasienter hatt restriktiv ventilasjonsinnskrenkning på bakgrunn av stabile ekstrapulmonale tilstander (skoliose, postpoliosyndrom) og langsomt progredierende nevrologisk sykdom. Dokumentasjon på nytteverdien av behandlingen er klart størst i disse gruppene (6), og ut fra dagens kunnskap bør disse pasientene prioriteres. For pasienter med amyotrofisk lateral sklerose er det god dokumentasjon på behandlingseffekt ut fra overlevelse, palliasjon og bedret livskvalitet (4), selv om overlevelsen er lavere enn hos andre hjemmerespiratorpasienter (7). Tidspunkt for oppstart av hjemmerespiratorbehandling hos disse pasientene bør i størst mulig grad være planlagt, og det bør diskuteres på forhånd hvorvidt man skal velge trakeostomi som ventilasjonstilslutning. Masketilpasning kan være en utfordring ved bulbær affeksjon hos pasientene, men flere studier viser bedret livskvalitet og høyere overlevelse også ved maskebehandling $(8,9)$.

Gjennom de siste ti årene har det i flere land, også i Norge, vært en endring i pasientseleksjonen når det gjelder voksne (10), med økende hjemmerespiratorbehandling ved tilstander som adipositashypoventilasjonssyndrom (11) og stabil kols (12). Ubehandlet har pasienter med adipositashypoventilasjonssyndrom stort forbruk av helsetjenester, økt morbiditet og tidligere mortalitet (13). Nytteverdien av hjemmerespiratorbehandling med ventilasjon via maske er godt dokumentert - med bedring i objektive variabler (bedre nattlige blodgassnivåer og redusert REM-søvnhypoventilasjon), bedret livskvalitet og høyere overlevelse (14).

På grunn av dårlig kvalitet på mange studier er det vanskelig å trekke holdbare konklusjoner om indikasjon for hjemmerespiratorbehandling ved stabil kols (15). I to store internasjonale oversiktsartikler $(12,15)$ har man konkludert med at ventilasjon via maske hos stabile kolspasienter i randomiserte studier over 1-2 år verken har vist reduksjon i antall sykehusinnleggelser, effekt på lungefunksjon, gassutveksling, respirasjonsmuskelstyrke, søvnkvalitet eller fysisk toleranse (6 min gangtest) og at behandlingstilbudet ikke rutinemessig bør gis denne pasientgruppen. Ut fra dagens dokumentasjon bør denne anbefalingen være veiledende.

Medisinske kriterier for oppstart av hjemmerespiratorbehandling må være veldefinerte og basert på holdbare forskningsmessige konklusjoner forankret $\mathrm{i}$ en nasjonal
Tabell 2 Årsak til oppstart av hjemmerespiratorbehandling hos voksne (1 149 voksne totalt)

\begin{tabular}{|c|c|c|}
\hline Diagnoser & Antall & $(\%)$ \\
\hline $\begin{array}{l}\text { Stabil kronisk obstruktiv } \\
\text { lungesykdom (kols) }\end{array}$ & 272 & $(23,7)$ \\
\hline $\begin{array}{l}\text { Adipositashypoventilasjons- } \\
\text { syndrom }\end{array}$ & 250 & $(21,8)$ \\
\hline $\begin{array}{l}\text { Amyotrofisk lateral sklerose } \\
\text { (ALS) }\end{array}$ & 108 & $(9,4)$ \\
\hline Postpoliosyndrom & 102 & $(8,9)$ \\
\hline $\begin{array}{l}\text { Fascio-scapulo-humeral } \\
\text { dystrofi/limb girdle muscu- } \\
\text { lar dystrophy }\end{array}$ & 28 & $(2,4)$ \\
\hline Annen muskeldystrofi & 28 & $(2,4)$ \\
\hline $\begin{array}{l}\text { Idiopatisk skoliose/skjelett- } \\
\text { dysplasi }\end{array}$ & 27 & $(2,3)$ \\
\hline $\begin{array}{l}\text { Høy ryggmargskade/tverr- } \\
\text { snittslesjon }\end{array}$ & 26 & $(2,3)$ \\
\hline Tuberkulosesekvele & 26 & $(2,3)$ \\
\hline Dystrophia myotonica & 26 & $(2,3)$ \\
\hline Cheyne-Stokes-respirasjon & 25 & $(2,2)$ \\
\hline $\begin{array}{l}\text { Duchennes/Beckers mus- } \\
\text { keldystrofi }\end{array}$ & 23 & $(2,0)$ \\
\hline $\begin{array}{l}\text { Sentralt hypoventilasjons- } \\
\text { syndrom }\end{array}$ & 22 & $(1,9)$ \\
\hline Spinal muskelatrofi (SMA) ${ }^{1}$ & 14 & $(1,2)$ \\
\hline Multippel sklerose & 13 & $(1,1)$ \\
\hline Lungeparenkymsykdom & 11 & $(1,0)$ \\
\hline Polynevropati & 8 & $(0,7)$ \\
\hline Hjerneskade & 8 & $(0,7)$ \\
\hline Cystisk fibrose & 4 & $(0,3)$ \\
\hline Cerebrale misdannelser & 3 & $(0,3)$ \\
\hline Mitokondriell sykdom & 2 & $(0,2)$ \\
\hline Degenerativ hjernesykdom & 2 & $(0,2)$ \\
\hline Andre indikasjoner ${ }^{2}$ & 121 & $(10,4)$ \\
\hline
\end{tabular}

konsensus. Nasjonalt kompetansesenter for hjemmerespiratorbehandling er bygd på en nettverksmodell med medarbeidere $i$ alle helseregioner. På sikt vil dette bidra til at kompetansen innenfor denne behandlingsformen blir mer jevnt fordelt mellom regionene. En tydelig ansvarsfordeling regionalt kan føre til en enhetlig praksis og høyere kvalitet på tjenesten. Spørsmål om best mulig ressursutnyttelse er viktig. Hvorvidt behandlingen startes opp akutt eller planlagt vil kunne gi store utslag når det gjelder lengden på sykehusoppholdet. Velger man trakeostomi ved hjemmerespiratorbehandling, blir omsorgen svært ressurskrevende sammenliknet med ventilasjon via maske. Spesialisthelsetjenesten bør tidlig ta kontakt med førstelinjetjenesten når behandlingen krever pleie- og omsorgstjenester eller tilrettelegging av forholdene i hjemmet. Trakeostomerte, spesielt pasienter med raskt progredierende sykdom, har et stort pleiebehov 
som kan medføre en betydelig utfordring for førstelinjetjenesten, både økonomisk og når det gjelder tilgang på kompetent personell. Dette er forhold som kan innvirke på ulikheter i behandlingstilbudet.

For at Nasjonalt register for hjemmerespiratorbehandling skal kunne brukes til forskningsformål er det viktig at opplysningene er komplette og korrekte når det gjelder gruppen hjemmerespiratorpasienter. Som ledd i motiveringen for å registrere pasienter har registeret siden 2006 sendt årlige regionale rapporter til alle sykehus som har meldt inn pasienter. Kompetansesenterets medarbeidere $\mathrm{i}$ alle helseregioner har også som oppgave å informere om og motivere for registrering, både blant kolleger og overfor pasientene. Registeret er samtykkebasert, noe som kan vanskeliggjøre komplett innrapportering. Ved direkte kontakt med alle sykehus var det ingen leger som opplyste at pasienter ikke ga samtykke til registrering, men noen leger sa at de $i$ en travel hverdag ikke hadde tid til å fylle ut skjemaer. På bakgrunn av opplysninger fra behandlende leger er anslagsvis opp mot $90 \%$ av hjemmerespiratorpasientene registrert, og det er ingen holdepunkter for å tro at registreringen er mer komplett i noen helseregioner enn $\mathrm{i}$ andre. Det var heller ingen variasjoner mellom helseregionene i forhold til hvor fullstendig hvert enkelt skjema var utfylt. Samarbeid mellom sykehusenes medisinsktekniske avdelinger og Nasjonalt register for hjemmerespiratorbehandling ved at man rapporterer utlevering av utstyr kan være én måte å oppnå så komplett innrapportering som mulig.

Oppgitte interessekonflikter: Ingen

\section{Litteratur}

1. Fauroux B, Howard P, Muir JF. Home treatment for chronic respiratory insufficiency: the situation in Europe in 1992. The European Working Group on Home Treatment for Chronic Respiratory Insufficiency. Eur Respir J 1994; 7: 1721-6.

2. Lloyd-Owen SJ, Donaldson GC, Ambrosino N et al. Patterns of home mechanical ventilation use in Europe: results from the Eurovent survey. Eur Respir J 2005; 25: 1025-31.

3. Laub M, Berg S, Midgren B. Home mechanical ventilation in Sweden - inequalities within a homogenous health care system. Respir Med 2004; 98 : $38-42$.

4. Simonds AK. Home ventilation. Eur Respir J Suppl 2003; 47: 38s-46s.

5. www.helse-bergen.no/avd/hjemmerespiratorbehandling/ (18.6.2009).

6. Simonds AK, Elliott MW. Outcome of domiciliary nasal intermittent positive pressure ventilation in restrictive and obstructive disorders. Thorax 1995; 50: $604-9$

7. Laub M, Midgren B. Survival of patients on home mechanical ventilation: a nationwide prospective study. Respir Med 2007; 101: 1074-8

8. Kleopa KA, Sherman M, Neal B et al. Bipap improves survival and rate of pulmonary function decline in patients with ALS. J Neurol Sci 1999. 164: 82-8.

9. Lyall RA, Donaldson N, Fleming T et al. A prospective study of quality of life in ALS patients treated with noninvasive ventilation. Neurology 2001: 57: 153-6.

10. Janssens JP, Derivaz S, Breitenstein E et al. Changing patterns in long-term noninvasive ventilation:

Forekomst per 100000

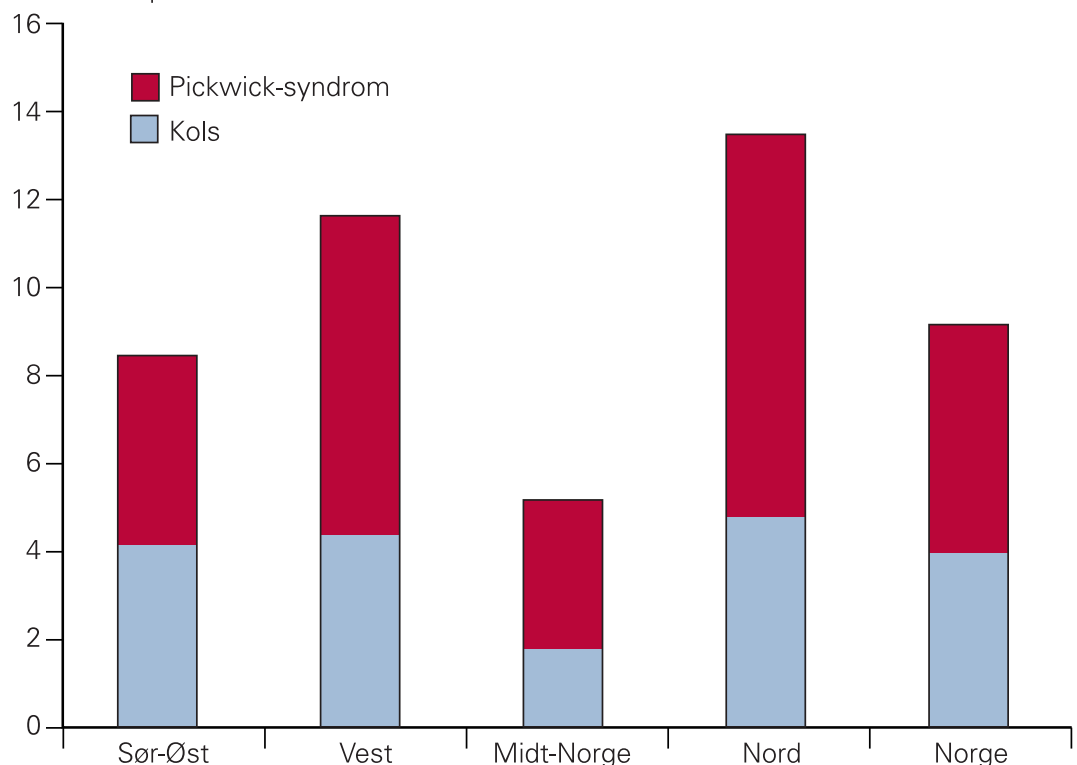

a

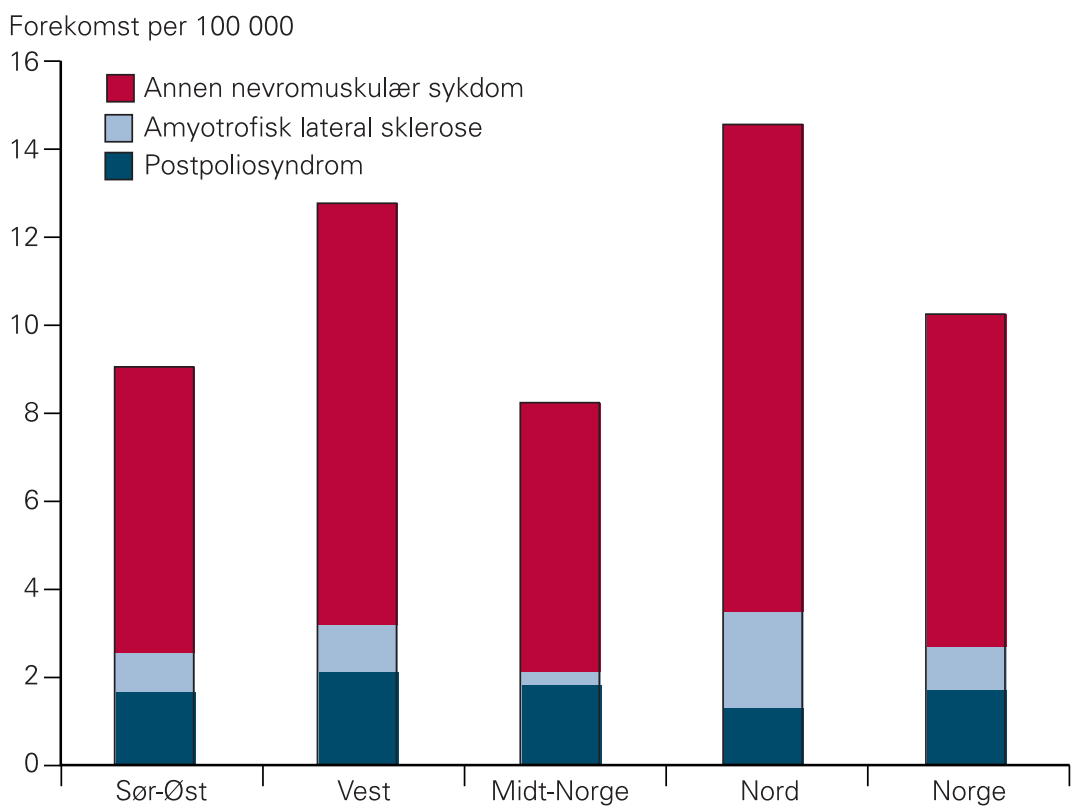

b

Figur 3 Forekomst av hjemmerespiratorpasienter fordelt på helseregioner og stratifisert ut fra de vanligste grunnlidelsene

a 7-year prospective study in the Geneva Lake rea. Chest 2003; 123: 67-79.

11. Masa JF, Celli BR, Riesco JA et al. The obesity hypoventilation syndrome can be treated with noninvasive mechanical ventilation. Chest 2001. 119: 1102-7.

12. Wijkstra PJ, Lacasse Y, Guyatt GH et al. A metaanalysis of nocturnal noninvasive positive pressure ventilation in patients with stable COPD. Chest 2003: 124: 337-43.

13. Nowbar S, Burkart KM, Gonzales R et al. Obesityassociated hypoventilation in hospitalized patients: prevalence, effects, and outcome. Am J Med 2004 116: 1-7.

14. Chouri-Pontarollo N, Borel JC, Tamisier R et al. Impaired objective daytime vigilance in obesityhypoventilation syndrome: impact of noninvasive ventilation. Chest 2007; 131: 148-55.
15. Struik FM, Duiverman G, Bladder G et al. Effects of non-invasive positive pressure ventilation (NIPPV) in stable chronic obstructive pulmonary disease (COPD). Respir Med 2008; 4: 94-100.

Manuskriptet ble mottatt 27.12. 2008 og godkjent 18.6. 2009. Medisinsk redaktør Anne Kveim Lie. 